\title{
Asperger Syndrome and the Children who 'Don't Quite Fit In'
}

\author{
SUZY PORTWAY ${ }^{*}$ and BARBARA JOHNSON ${ }^{\mathrm{b}}$ \\ ${ }^{a}$ Health Visitor, West Sussex NHS Primary Care Trust, The Surgery, Torton Hill Road, Arundel, West \\ Sussex BN18 9HF, UK; 'b St Bartholomew's School of Nursing and Midwifery, City University, London, UK
}

\begin{abstract}
This paper discusses some of the early findings of current Ph.D. work exploring the lives of young adults with Asperger Syndrome and their parents. The focus here is the experience of 'growing up' as perceived by people with Asperger Syndrome. The findings relating to the experience for parents and outcomes for families will be the subject of further papers. For the main study, twenty-five families were purposively sampled and informal interviews conducted with young adults with Asperger Syndrome and their parents. Participants with Asperger Syndrome were encouraged to talk about their own life story. Interviews were transcribed and constant comparative analysis used to identify, compare and code common themes across the data. The stories told are powerful accounts of children who from an early age 'looked normal, talked normal' but never seemed to 'quite fit in'. They went through school and moved into adulthood feeling and being treated as 'different', with nobody seemingly understanding why. Many were excluded educationally, in that some were expelled from school while others were excluded by their peers within school, thus leaving them feeling 'outsiders'. All the participants expressed views that likened them to living on the edge of society where they felt extremely isolated and vulnerable to mental health problems. The findings suggest the need for greater knowledge of Asperger Syndrome among preschool workers, teachers and health care professionals. The importance of earlier detection and the appropriate educational, social and emotional support to help prevent a constant catalogue of negative experiences is emphasised. It is argued that such measures will maximise the opportunities for developing a positive self-image as well as intellectual and personal achievement.
\end{abstract}

Key words: Children; Asperger Syndrome; Early diagnosis; Not fitting in

\section{INTRODUCTION}

The aim of the study was to explore the life experience of young adults with Asperger Syndrome aged between 18 and 35 years, both from their own and their parents' perspective. For the purpose of this paper the findings discussed relate only to one aspect of the larger study; that of childhood experiences in relation to health outcomes in adulthood. The analysis draws on the retrospective childhood accounts of young adults with Asperger Syndrome and the accounts of early childhood provided by parents. When the study was first commissioned there continued to be some controversy surrounding the definition of Asperger Syndrome (Cox, 1991; Gross, 1994; Schopler, 1996). However, it is now widely considered to belong to the wider spectrum of autism disorders (Medical Research Council, 2001; National Autistic Society, 1999a; Wing, 1981, 1996). The background to such debates and the history of autism and Asperger Syndrome is considered to be extremely important in reflecting on the findings of the study.

\footnotetext{
*Corresponding author.
} 


\section{BACKGROUND}

First I was autistic, and then I was a person with autism, now I have an autistic spectrum disorder! (Blackburn, 2002)

Asperger Syndrome is a lifelong developmental disorder belonging to the family of autism spectrum disorders (Wing, 1996). In comparison with the term 'autism', which first gained recognition following the publication of Kanner's (1943) seminal work, Asperger Syndrome represents a relatively new diagnostic category that has gained increasing recognition over the past 20 years. This is despite the fact that Asperger's work was published in 1944, only 1 year after that of Kanner. Both were Austrian physicians; Kanner lived and worked in the US and his work was published in English and became widely acknowledged, while Asperger's work was published in German and remained relatively obscure until the early 1980s. At that time Wing (1981) published a detailed account of thirty-four cases similar to those described by Asperger and introduced the term Asperger Syndrome as a more acceptable alternative to Asperger's term autistic psychopathy. The work of both Kanner and Asperger are summarised in detail by Frith (1991), but it is worth noting that they both independently identified forms of autism now widely understood to be at differing ends of an autism spectrum. The children Kanner observed would today be described by Jordan (2001) as having the dual disability of autism and a learning disability, whereas the children Asperger observed were more able children with autism who, while not demonstrating a defined learning disability, did have specific areas of learning difficulty.

The notion of a spectrum of autism disorders was first put forward by Wing and Gould (1979), and this has recently gained wider acceptance and application (Attwood, 1998; Medical Research Council, 2001; National Autistic Society, 1999a). The autism spectrum covers a range of ability levels and degrees of severity but it is characterised by qualitative impairments in social, communicative and imaginative development known as the 'triad' of impairments (Wing, 1996; Wing and Gould, 1979).

People with Asperger Syndrome have a normal to high intellect but, as with all people with autism spectrum disorders, they are affected to differing degrees in they way they think, communicate, relate to others and understand the world around them (National Autistic Society, 1999a). However, children with Asperger Syndrome can and often learn strategies for coping that can mask the true extent of their difficulties (National Autistic Society, 1999b). They do not usually look as if they have a disability and they will often appear to speak well. To some degree they may integrate socially, although they may appear aloof, awkward, shy or otherwise overly friendly and intrusively talkative (Wing, 1996). It is this outward appearance of 'normality' that can confuse parents and professionals and lead to the condition being unrecognised and undetected for many years (Holliday Willey, 1999).

\section{THE STUDY AND SAMPLE}

This study grew out of a 3 year project undertaken with a small autism support group that surveyed the needs of children and adults living in the south of England (Portway, 2000). The purpose was to explore the life experiences of young adults with Asperger Syndrome and their parents. A qualitative design was chosen and the methods used were informed by grounded theory methodology (Glaser and Strauss, 1967; Strauss and Corbin, 1998), which enables the identification of common themes while also encompassing and contending with the natural differences that exist by virtue of people's individualities: differing experiences, circumstances and personalities. Of the twenty-five families included in the study, eighteen young adults with Asperger Syndrome and sixteen parents were interviewed. Each participant 
and interview was approached individually. How and where the interviews were conducted varied according to participants' preferences and personal circumstances. Some adults and parents were interviewed jointly, some separately; some took place in their homes, some at the local autism support group office. One interview with a parent was carried out in the garden of a remote country pub. While the intention was to audiotape all interviews, some participants preferred the researcher to make notes only. Tape-recorded interviews were transcribed and all data entered into the software programme QSR NVivo (QSR, 1999) for storage and management of both the raw and coded data.

Ethics approval was granted prior to the study. However, while careful consideration had been given to the potential difficulties that might arise for participants, many unforeseen practical and sensitive issues did come up during the process of data collection. Particular difficulties arose when trying to access potential participants and knowing who in a family to approach first. Another problematic area was interviewing people with Asperger Syndrome who by definition have social and communication difficulties, the extent of which was unknown to the researcher prior to the first meeting. On reflection, ethical considerations in such circumstances need to be part of an ongoing process. During the 3 years of the initial project, monthly steering group meetings and regular academic supervision provided appropriate support and steerage of the project.

\title{
FINDINGS AND DISCUSSION
}

The overall finding/core finding is that children with Asperger Syndrome do not 'quite fit in' to many aspects of life including babyhood, developmental patterns, schooling, expectations, friendships, and family life and society. A range of issues and concerns common to participants were identified and categorised, and all fit as subcategories of the core category 'not quite fitting'. Subcategories associated with early development (0-4 years) and the growing up years (5-17 years) reported in this paper include 'early differences in infancy', 'little loners', 'in school but not of school', and 'feeling different and unhappiness'.

\section{Early Differences in Infancy}

\author{
He was always so serious ... he didn't smile or coo like other babies. (Interview 7.2, mother) \\ He was a very stiff baby, always so tense he just couldn't ever relax. (Interview 3.2, mother) \\ If she was upset it would be no good cuddling her, she would prefer to be put down and left alone. \\ (Interview 4.2, father)
}

When recounting their child's early years, many parents reported differences in their children as early as the first year of life but at the time felt that their infants had not been quite 'different' enough to pinpoint what might be wrong or that there might be any lasting significance. Parents varied considerably about the time when they first thought that something with their child might not be 'quite right'. Whereas some parents reported that they had felt from very early on that something was different, others said that in the very early years they had had no idea that anything might be 'wrong'. However, with the benefit of hindsight all interviewed parents recalled aspects of unusual behaviour in their young infants. One striking example of the difficulties associated with unusual behaviour came from one mother who talked about her baby son's peculiar and intense preference for a yellow dummy:

From a little baby he would refuse to suck on anything other than a yellow dummy, it had to be yellow or he would scream for ages .... and so I ended up buying yellow dummy's wherever I could get them so I wouldn't run out of them, not to have a yellow dummy was hell. (Interview 17.2, mother) 
It is of course important to remember that all infants are different to each other anyway and so it is easy for both parents and professionals to miss a potentially significant clue in the very early years.

\section{Little Loners}

Stephen was rarely invited to birthday parties and he never wanted one of his own, he was my little loner. (Interview 10.2, mother)

William's a loner, he always was, the teacher once said to me "he is a very strange little boy he quite often just stands on his own and looks, he doesn't participate with the other children". (Interview 3.2, mother)

Parental accounts of their child's early years describe many examples of ways in which their children did not 'quite fit in' from an early age. Many parents talked about their young child's reluctance to 'join in' with other children, and some described their children as 'little loners'. They described ways that their child did not quite fit with reference to developmental norms. For example, they were quick to learn in some ways (i.e., literacy, numeracy, puzzles, computer games) but slower in other ways (notably with social talk and play). Children were described as having been both very timid and awkward or hyperactive and overly talkative, and many parents were concerned at the time that something might be untoward. It is interesting to note that such descriptions have become classic pictures of the developmental profile of children along the autism spectrum (Attwood, 1998; Jordan and Powell, 1995; Wing, 1996, 1981), and yet many children with Asperger Syndrome remain undiagnosed into adolescence and adulthood (National Autistic Society, 1999b).

\section{In School But Not of School}

At school I was always teased by the other children, they would call me names, throw stones, and pull my hair ... there was one boy, but even he was only a friend when it suited him, when there was no one else to play with, he was only a superficial friend. (Interview 19.1, Paul, aged 23 years)

I was unhappy there [school], well because, you know getting on with other people, I just couldn't relate to anyone and I couldn't, you know, form any type of friendship with anyone and I was never happy with the work that I was doing because I was never satisfied that it was perfect enough and I got really stressed over it. Um, so I didn't enjoy it because I got so stressed about it, I became so depressed that I couldn't take my GCSE's and didn't get any qualifications there. (Interview 3.1, William, aged 19 years)

The school years were seen by people with Asperger Syndrome as being particularly and progressively problematic. School life became more and more difficult as they became older, and this seemed to be related to the increasing social expectations from the child themselves as well from peers, teachers, parents and society in general. The transition from childhood to adolescence was seen as especially disruptive by parents for the entire family. The pressures of growing up and increasing social expectations became compounded by the difficulties that are typical in autism such as difficulty in coping with the greater flexibility of becoming less dependent, more choice and increasing responsibility. Parents highlighted this as a time of tremendous stress for all the family and a time of intense vulnerability for their child with Asperger Syndrome. Secondary school memories recalled by some participants were particularly harrowing and all viewed this period in their lives with considerable negativism. This period was also a source of considerable concern for parents who highlighted the problems for their child in coping with a range of things such as the increased size of schools and complicated timetables and routines, as well as the number of different teachers involved on a daily basis meaning less time for teachers to understand the child with Asperger Syndrome. For parents with financial means, private schooling was often the preferred choice as it offered smaller physical environments and smaller class sizes. However, private education was not always seen to be advantageous. Parents described how they lacked 
recourse to a higher education authority when difficulties arose, and they also complained of a general lack of understanding and provision of special needs education within private schools. Exclusion from school was alarmingly common with a total of seven participants having been excluded from one or more schools: five were expelled by the school; one was taken out of school by his parents (for home tuition as they believed he was being severely bullied by a teacher as well as pupils); and one young teenager effectively excluded herself by simply refusing to go to school:

I was sick every morning before I had to go. My father was so strict; he wanted me to get there and would drag me into the car. One morning we got there and I didn't get out and he shouted. I still wouldn't get out so he drove to work and I stayed in the car while he was at work all day. ... So then I had to see another educational psychologist who said I had to go to school. I burst into tears because I just couldn't do it. (Interview 15.1, Rachel, aged 33 years)

The high number of school exclusions in this study is not unusual among children with autistic spectrum disorders. Barnard, Harvey, Potter, and Prior (2001) report that children with autistic spectrum disorders are on average twenty times more likely to be excluded from school than their peers, with one in five (21\%) excluded at least once, compared with $1.2 \%$ of the total pupil population.

It is interesting to note that parents referred to their children as being 'in school but not of school', in that they attended their local mainstream school but did not fit into the school system or with their peer groups. Their children always seemed to have problems joining in school activities and making friends. Many parents felt that their children were not nurtured at school but rather had been misunderstood, bullied and ostracised by peers and teachers alike. At best these children simply existed at school, at worst the school system seemed to have damaged them further. Both parents and those with Asperger Syndrome felt they had been failed by their respective schools.

\section{Feeling Different and Unhappiness}

I remember feeling quite uncomfortable around people, straight away I realised I was not right, it was just a sort of vague uncomfortable feeling that grew as I grew. (Interview 6.1, Ben, aged 27 years)

Its funny because Asperger's Syndrome is not like autism, it is a subdivision sure but in essence when you think about perception wise and the pain, the real severity of the pain that the individuals will go through, it is the opposite. I think that autistic people are in a world of their own, they are oblivious to things that go on outside them and so they are contented with the way they are, this is what I think. And you know I wish I was like that, in terms of affliction, in terms of the depths that you go to, the emotional depths that you go to Asperger's is a lot more, umm, deadly. (Interview 3.1, William, aged 19 years)

From an early age the experience of feeling 'different' was very real to some of these young people. Those with Asperger Syndrome highlighted the pain of feeling different from others on many occasions. It is this inner awareness of difference that for some can make living with Asperger Syndrome so difficult. For those with Asperger Syndrome, the self- 'perception' of being different and feelings of inadequacy were described as being a major cause of inner pain and suffering. The usual pleasures of socialising, of friendships and close relationships seemed to be denied to them, yet the desire to be like other people was intense. They saw their peers 'joining in' and seemingly enjoying the company of others, and many wanted to be able to join in too.

I would often stand in the playground or sit in class and just watch others ... playing together, talking, laughing, joking - having fun, I wished I could join in or have a special friend but I never really did, I would usually be on my own, just like an outsider looking in. (Interview 20:1, Sebastian, aged 28 years)

Participants varied greatly in how they perceived themselves socially and the degree to which they wanted to mix more with others. There seemed to be a scale on which participants were both 'able' and 'wanting' to be with other people, most preferring one to one friendships than 
groups. Wherever they were on the scale of sociability they all perceived themselves to be different. They were constantly teased and bullied but appeared to lack the mental agility and social skill necessary for self-defence. Consequently, many either withdrew from social situations or, when confronted with stressful encounters, they simply exploded verbally and/ or physically from the frustration and anger, which in turn led them to being shunned and isolated even more. The consequence for many of these young people was a downward spiral of unhappiness, anxiety, and depression.

It is disconcerting to find that twenty-three of the twenty-five young adults included in the study had, since childhood, experienced enduring problems linked to anxiety, depression and/ or severe and limiting obsessive behaviours. The combination of psycho-social factors 'within and without' these individuals may help us to understand the extent of their vulnerability. For example, psychologist Leenaars (1990) suggests that those prone to depression are people characterised by having more polarised, less imaginative and more constricted thought processes - a picture that fits precisely with the characteristics of Asperger Syndrome and the participants in the present study. In addition to such restricted thought processes, these young people lack close confiding friendships and wider supportive social networks that are increasingly being identified as important for positive health outcomes (Brugha,Wing, Brewin, MacCarthy, and Lesage, 1993; Ivar Elstad, 1998; Williams, Popay, and Oakley, 1999). If the degree of social isolation that exists for young people with Asperger Syndrome is combined with their inflexible thought processes and limited psychological coping mechanisms, it is not unreasonable that they become highly vulnerable to depression and poor long-term mental health outcomes. The high degree of psychological distress among the participants with Asperger Syndrome is in itself troubling, but even more troubling is the suicide risks it poses. A review of empirical suicide research by Gomm (1996) found that suicides are linked to gender and age (younger men), depression and anxiety, unskilled and unemployed, low self-esteem, isolation and poor social integration, and lack of problem-solving skills. Many of these risk factors square with the features of the participants in the present study. Their lives appeared to be very fragile and the only people who had recognised this were their parents, who in turn were saddened by their child's unhappiness but also fearful that they may resort to suicide.

\section{CONCLUSION}

With Philip we were always trying to put a square peg into a round hole, if the hole was big enough he would fall right through without being noticed, if it was too small he wouldn't get anywhere, often he could be forced in, but it was always an uncomfortable fit, whatever he would always end up being hurt.

(Interview 2.2, father)

The core finding in this study is of people who have not quite fitted into the normal patterns of life and relationships from an early age. When discussing the findings of any study concerning people, their lives and experiences, it is important to remember that no two people are the same and differences will always exist. Likewise, no two people with Asperger Syndrome are the same; how it affects a person or family and the experience of living with Asperger Syndrome is different for every person and family. There is always an intricate and potentially creative interaction between the characteristics of autism and the other qualities of the individual and their environment (Sacks, 1985). This does not mean that common experiences do not exist or that connections cannot be made, especially since the core features of autism have been shown to be remarkably consistent over time (Asperger, 1944; Attwood, 1998; Kanner, 1943; Sacks, 1985; Wing, 1981). In this study all the life stories shared are individual, but they do highlight particular difficulties associated with living with Asperger Syndrome in today's society. It should be noted that only four of the twenty-five 
young adults with Asperger Syndrome sampled had a childhood diagnosis of Asperger Syndrome; the youngest was diagnosed at 12 years old. In recent years many children are diagnosed earlier than this but, according to The National Autistic Society (1999b), diagnoses are still not made early enough. Further research is necessary to consider the difference an early diagnosis makes to childhood experience, schooling and outcomes in adulthood.

The findings from this study have shown that people with Asperger Syndrome feel that throughout their lives they have neither quite 'fitted in' nor quite 'stood out'. They live on the very edge of what society thinks of as 'normal', and this has had a particular impact in terms of their individual needs being adequately met, for example, not being offered specialist help, specialist schooling or the kind of support needed to help a child integrate into mainstream school. Such provision is generally afforded only to those who are clearly recognised as 'different'.

In this study, 'not quite fitting' refers to many different aspects of the young person's life including babyhood, developmental patterns, schooling, expectations, friendships, family life and life generally. Although early 'differences' in infancy were recognised by parents, autism was not suspected during the preschool years. However, once at school, life became more and more demanding; not necessarily academically, but certainly socially. The experience of being bullied was a recurring theme while making friends was exceptional. Over time the expectations of self and others became increasingly difficult to meet, while depression during adolescence and young adulthood was not uncommon.

The concept of not quite fitting in is significant in that the kind of disability children with Asperger Syndrome experience is rarely obvious to the onlooker but neither are their differences completely veiled. Their abilities and disabilities are inconsistent in that they can be highly able in some ways (i.e., academically), and surprising inept in others (e.g., in peer interaction). Coupled with the areas of high aptitude, their ability to socially integrate, albeit at a fairly superficial level, leaves parents and professionals confused and baffled. Thus in their case, ability succeeds in hiding their disability. The higher their level of ability, the more difficult it is to 'see' their level of vulnerability. This in turn leads to delays in seeking and/or receiving help, leaving the child at risk of negative encounters, developing low self-esteem, anxiety and depression (Craig, 1998; Smith and Sharp, 1994; Thompson, 2000). We suggest that the wounds of childhood bullying and inappropriate management of difficult behaviour, as well as the missed educational opportunities, make the management of problems in adulthood extremely difficult if not almost impossible.

The question of how education, health and social service professionals should respond to calls for early identification and intervention is not simple. Needs across the autism spectrum are complex and diverse. Earlier detection and better understanding of Asperger Syndrome from those who are in regular contact with the child, along with better preparation for starting school and better educational and peer support within schools, is likely to make a significant difference to the long-term outcome for such children. The long-lasting and damaging effects of bullying are well documented (Craig, 1998; Smith and Sharp, 1994; Thompson, 2000), with the health-enhancing effects of friendships and supportive social networks (Brugha et al., 1993; Ivar Elstad, 1998; Williams et al., 1999) being equally well documented. A relatively simple and achievable approach to helping children and young people with Asperger Syndrome realise their full potential for achievement and promote positive health is to assist them to gain full access to the opportunities that already exist within families, schools and communities by training, sensitising and supporting those who already provide these essential resources for living (i.e., parents, preschool workers, health visitors, doctors, school nurses, teachers, social workers and careers advisors, to mention but a few). This is not intended to be a simple or indeed a frivolous answer to a complex problem. The argument is that many families can be helped by support systems already in place if, and only if, the individuals involved understand 
just what it means to individuals and families to live with Asperger Syndrome. It is worth emphasising that some people with Asperger Syndrome will never cope well within mainstream services and for them more specialised help will be necessary. Indeed, to fit with meeting the needs of the autism spectrum, there needs to be a spectrum of service provision ranging from separate specialist schools and residential placements to semi-supported provision through to fully independent living. To help the many people living with minimal specialist support, we advocate the capacity building of existing resources with widespread training and education to help people understand the behaviours of children (and adults) with Asperger Syndrome. Such understanding will go a considerable way to helping children (and adults) to 'fit in' more effectively. An example of taking such understanding into practice would be to teach youth leaders how to provide opportunities for children with Asperger Syndrome in mainstream youth club activities and play schemes.

For help to be initiated, children need to be diagnosed as early in their lives as possible. It remains the case that many children are not diagnosed before they commence school at 5 years of age (Howlin and Moore, 1997; National Autistic Society, 1999b; Portway, 2000). The many abilities of children with Asperger Syndrome can still make it difficult for parents and professionals who are not familiar with the complexities of the autism spectrum to identify their true difficulties in the formative years. Currently, routine child health surveillance programmes undertaken by health visitors and general practitioners screen for either physical abnormalities or learning disabilities where there are global developmental delays in general development and learning. In Asperger Syndrome the developmental picture is far from global or clear-cut; there is a divide between the outward appearance of normality and the existence of subtle but very profound differences, and this confounds families and professionals and leads to delays in early identification, diagnosis and the provision of helping strategies. Health visitors, general practitioners and all preschool workers are in key positions to be recognising and referring onwards problems pointing to possible Asperger Syndrome in the children who may 'look normal, talk normal', but just do not quite 'fit in'.

\section{References}

Asperger, H. (1944) Die autistischen psychopathen im kindesalter (Autistic psychopathy in childhood), In: Frith, U. (Ed.) (1991), Autism and Asperger Syndrome. Cambridge: Cambridge University Press.

Attwood, T. (1998) Asperger's Syndrome: A Guide for Parents and Professionals. London: Jessica Kingsley Publishers.

Barnard, J., Harvey, V., Potter, D. and Prior, A. (2001) Ignored or Ineligible? The Reality for Adults with Autistic Spectrum Disorders. London: The National Autistic Society.

Blackburn, R. (2002) What is it like to have autism? Talk given at Autism Awareness Policy and Strategy Conference, The King's Fund, London, 14 February.

Brugha, T., Wing, J., Brewin, C., MacCarthy, B. and Lesage, A. (1993) The relationship of social network deficits with deficits in social functioning in long-term psychiatric disorders, Social Psychiatry and Psychiatric Epidemiology, 28, 218-224.

Cox, A. (1991) Is Asperger's Syndrome a useful diagnosis?, Archives of Diseases in Childhood, 66, 259-262.

Craig, W. (1998) The relationship among bullying, victimisation, depression, anxiety and aggression in elementary school children, Personality and Individual Differences, 24, 123-130.

Frith, U. (Ed.) (1991) Autism and Asperger Syndrome. Cambridge: Cambridge University Press.

Glaser, B. and Strauss, A. (1967) The Discovery of Grounded Theory. New York: Aldine Publishing Company.

Gomm, R. (1996) Reversing deviance, In: Heller, T., Reynolds, J., Gomm, R., Muston, R. and Pattisson, S. (Eds.), Mental Health Matters. London: The Open University.

Gross, J. (1994) Asperger Syndrome: a label worth having?, Educational Psychology in Practice, 10(2), 104-110.

Holliday Willey, L. (1999) Pretending to be Normal. London: Jessica Kingsley.

Howlin, P. and Moore, J. (1997) Diagnosis in autism: a survey of over 1200 patients, Autism: The International Journal of Research and Practice, 1, 135-162.

Ivar Elstad, J. (1998) The psycho-social perspective on social inequalities in health, In: Bartley, M., Blane, D. and Davey Smith, G. (Eds.), The Sociology of Health Inequalitie. Oxford: Blackwell Publishers. 
Jordan, R. (2001) Autism with Severe Learning Difficulties. London: Souvenir Press.

Jordan, R. and Powell, S. (1995) Understanding and Teaching Children with Autism. London: John Wiley and Sons.

Kanner, L. (1943) Autistic disturbances of affective contact, Nervous Child, 2, 217-250.

Leenaars, A. (1990) Psychological perspectives on suicide, In: Lester, D. (Ed.), Current Concepts of Suicide. Philadelphia, PA: Charles Press.

Medical Research Council (2001) Review of Autism Research, Epidemiology and Causes. London: Medical Research Council.

National Autistic Society (1999a) The Autistic Spectrum - A Handbook. London: The National Autistic Society.

National Autistic Society (1999b) Opening the Door - A Report on Diagnosis and Assessment of Autism and Asperger Syndrome based on Personal Experiences. London: The National Autistic Society.

Portway, S. (2000) The Needs of Children and Adults with Asperger Syndrome Living in Berkshire. Reading: Berkshire Autistic Society.

QSR (1999) NVivo. Melbourne: Qualitative Solutions and Research.

Sacks, O. (1985) An Anthropologist on Mars. London: Picador.

Schopler, E. (1996) Are Autism and Asperger Syndrome different labels or different disabilities? Journal of Autism and Developmental Disorders, 26(1), 109-110.

Smith, P. and Sharp, S. (Eds.) (1994) School Bullying: Insights and Perspectives. London: Routledge.

Strauss, A. and Corbin, J. (1998) Basics of Qualitative Research - Grounded Theory Procedures and Techniques (2nd ed.). London: Sage Publications.

Thompson, D. (2000) Bullying and harassment in and out of school, In: Aggleton, P., Hurry, J. and Warwick, I. (Eds.), Young People and Mental Health. Chichester: John Wiley.

Williams, F., Popay, J. and Oakley, A. (1999) Welfare Research: A Critical Review. London: UCL Press.

Wing, L. (1981) Asperger Syndrome: a clinical account, Journal of Psychological Medicine, 11, 115-129.

Wing, L. (1996) The Autistic Spectrum: A Guide for Parents and Professionals. London: Constable.

Wing, L. and Gould, J. (1979) Severe impairment of social interaction and associated abnormalities in children: epidemiology and classification, Journal of Autism and Developmental Disorders, 9, 11-29. 
Copyright of Early Child Development \& Care is the property of Carfax Publishing Company and its content may not be copied or emailed to multiple sites or posted to a listserv without the copyright holder's express written permission. However, users may print, download, or email articles for individual use. 